\title{
FUZZY SET THEORY-------- SOME USEFUL DISCUSSIONS AND INVESTIGATIONS
}

\author{
Surajit Bhattacharyya $1 \square$ (iD \\ ${ }^{1}$ Department of Mathematics Seth Anandram Jaipuria College, Kolkata (The University of Calcutta), West \\ Bengal, India
}

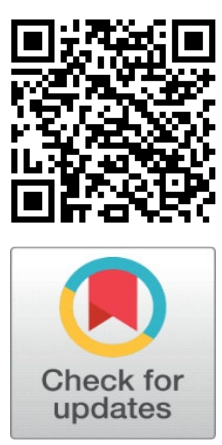

\section{ABSTRACT}

In this paper I have discussed some basic but very important theories of fuzzy set theory with numerous examples. I have investigated $\alpha$-sets, operations of fuzzy numbers, on interval fuzzy sets and also on fuzzy mappings. I have introduced S.Bs. class of fuzzy complements with its increasing and decreasing generators.

Received 15 July 2021

Accepted 30 July 2021

Published 31 August 2021

\section{CorrespondingAuthor}

Surajit Bhattachaaryya,

surajit_bhattacharyya@yahoo.com

DOI

10.29121/granthaalayah.v9.i8.2021. 4124

Funding: This research received no specific grant from any funding agency in the public, commercial, or not-for-profit sectors.

Copyright: (C) 2021 The Author(s). This is an open access article distributed under the terms of the Creative Commons Attribution License, which permits unrestricted use, distribution, and reproduction in any medium, provided the original author and source are credited.
Keywords: The $\alpha$-Cut Sets, Fuzzy Unions, S.Bs. Class of Fuzzy Complements, Fuzzy Numbers

\section{INTRODUTION}

In classical set theory, an entity can either belong to a set or not; and in optimization, a solution is either feasible or not. Precision assumes that the parameters represent exactly either our perception of the phenomenon modeled or the features of the real system that has been modeled. This is true for both the deterministic and the stochastic cases. Thus, according to the traditional view, mathematics must strive for certainty in all its manifestations (specificity, precision, sharpness, feasibility, consistency, etc.). Hence, uncertainty (nonspecificity, imprecision, vagueness, non-feasibility, inconsistency etc.) is regarded as unscientific.

Now, we have a question, why do we need to study fuzzy set theory?

Let us take an example. If we assume the probability of an element to be a member of a set is $80 \%$, the final conclusion is still either it is or it is not a member of the set. The chance for one to make a correct prediction for an element as it is a member of the set is $80 \%$, which does not mean that it has $80 \%$ membership in the set and at the same time it possesses $20 \%$ non-membership. That is, there is an ambiguity or uncertainty about an element to be a member or non-member of the set. In the classical set theory, it is not allowed an element to be a member of a set and not a member of the set at the same time. Thus, many real-world problems cannot be described and handled by the classical set theory. On the contrary, fuzzy set theory accepts partial memberships and thus to some extent generalizes the classical set theory. According to the modern view, uncertainty or fuzziness is considered essential to science, it is not only an unavoidable plague, but it has a great utility. 
When we calculate the profit of a company, we can't mention a particular percentage of profits as a modest profit. Its meaning is not totally arbitrary, however, we can't use "modest profit" to mean precisely profit of $80 \%$ and neither, in fact, is a profit of $40 \%$. If for, for any instance, a profit of $60 \%$ or more is considered modest, does it mean that a profit of $58 \%$ is not modest? This is clearly unacceptable, since, a difference of $2 \%$ profit hardly seems to be a distinguishable characteristic between the modest and not modest. But where do we draw the line? In order to resolve this paradox, the term modest may introduce vagueness by allowing some sorts of gradual transition from degree of profit that are considered to be modest and those are not. This is, in fact, precisely the basic concepts of fuzzy set, a concept that is both simple and intuitively pleasing and forms in a sense, a generalization of the classical or crisp set.

Fuzziness can be found in many areas of daily life, such as engineering, medicine, meteorology, manufacturing, management and so many. However, it is frequent in all areas in which human judgment, reasoning, learning, investigation, decision making are important. Generally, it is agreed that an important point in the evolution of the modern concept of uncertainty was the publication of a seminal paper by L. A. Zadeh [1965] .In this paper, Zadeh introduced a theory ---Fuzzy sets --- are sets with boundaries that are not precise .The membership in a fuzzy set is not a matter of affirmation or denial, but rather a matter of a degree.

When $A$ is a fuzzy set and ' $a$ ' is one of its elements, the proposition "a is a member of A" is not necessarily either true or false, but it may be true only to some degree, the degree to which ' $a$ ' is actually a member of the fuzzy A.

In general, we deal with problems in terms of systems that are constructed as models of either some aspects of reality or some desirable man-made objects .The purpose of constructing models of the former type is to understand some phenomenon of reality, be it natural or man-made, making adequate predictions or retrodictions, learning how to control the phenomenon in any desirable way and utilizing all these capabilities for various ends. Models of later type are constructed for the purpose of prescribing operations. In constructing a model, we always attempt to maximize its usefulness. This aim is closely connected with the relationship among three key characteristics of every system model: complexity, credibility and uncertainty. Our challenge in system modeling is to develop methods by which an optimal level of allowable uncertainty can be estimated for each modeling problem because allowing more uncertainty tends to reduce complexity and increase credibility of the resulting model.

In a paper L. A. Zadeh (1973) wrote, "As the complexity of a system increases, our ability to make precise and yet significant statements about its behavior diminishes until a threshold is reached beyond which precision and significance ( or relevance) become almost 
mutually exclusive characteristics ." as we know that , a complete description of a real system often would want far more detailed data than a human being could ever recognize, simultaneously process and understand.

In the natural languages, the meaning of words is very often vague. The meaning of a word might be well defined, but when using the word as a label for a set, the boundaries within which objects do or do not belong to the set become fuzzy or vague. Examples of such words are "animals", "birds", "big trees", "red flowers", "tall men", "good students", "beautiful women", "highly contagious diseases", "numbers much greater than 10 " and so many.

\section{RECALL:}

1) The support of a fuzzy set $\bar{A}$ within a universal set $U$ is the crisp set that contains all elements of $U$ that have nonzero membership grades in $\bar{A}$

2) The height of a fuzzy set is the largest membership grade obtained by any element in that set.

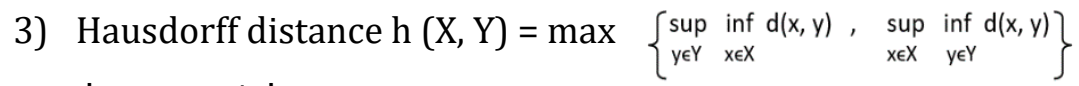
is symmetric.

4) Every fuzzy complement has at most one equilibrium.

5) Let $A=[A(i, j)]$ be an interval matrix. Then the real nonnegative matrix $w(A)=[w(A(i, j))]$ is called the width of A.

6) For interval matrices A, B, C, D we have the inclusion monotonic property like...

$$
\mathrm{A} \subseteq \mathrm{C} \text { and } \mathrm{B} \subseteq \mathrm{D} \Rightarrow \mathrm{A} \cap \mathrm{B} \subseteq \mathrm{C} \cap \mathrm{D} .
$$

7) The law of contradiction and law of excluded middle are violated for the fuzzy sets.

8) Every fuzzy number is a convex fuzzy set .

\section{CRISP SETS}

A classical or crisp set is generally defined as a collection of objects $x \in \mathrm{U}$, universal set. Each single element can either belong to or not belong to a set $A, A \subseteq U$. In the first case, the statement " $x$ belongs to $A$ " is true, while in the second case this statement is false.

We can define a crisp set in various ways: either by enumerating the elements that belong to the set; describing the set analytically like, $(\mathrm{A}=\{x \mid x \leq 10$ and a positive integer $\}$ ) i.e. set-builder form or defining the elements by using the characteristic function, in which 1 indicates membership and 0 indicates non-membership. 
A set can be defined by a function, usually called a characteristic function, that declares which elements of $U$ are members of that set and which are not. Set $A$ is defined by its characteristic function ${ }^{[1]} \chi_{A}$, as follows ........

$$
\chi_{A}(x)= \begin{cases}1, & \text { for } x \in A \\ 0, & \text { for } x \notin A\end{cases}
$$

This characteristic function maps elements of $\mathbf{X}$ to elements of the set $\{0,1\}$, which is usually expressed by

$$
\chi_{A}: U \rightarrow\{0,1\} .
$$

For each for $x \in \mathrm{U}$, when $\quad \chi_{A}(x)=1, x$ is declared to be a member of $\mathrm{A}$ and when $\quad \chi_{A}(x)=0, x$ is declared a nonmember of $\mathrm{A}$.

It is very much clear from the definition that a sharp, unambiguous distinction exists between the members and the nonmembers of the set.

\section{FUZZY SET}

A fuzzy set can be defined by assigning to each possible individual in the universe of discourse a value representing its grade of membership in the fuzzy set. This grade corresponds to the degree to which that individual is similar with the concept represented by the fuzzy set. Thus, individuals may lie in the fuzzy set to a greater or lesser degree as indicated by a larger or smaller membership grade.

The characteristic function [1], defined earlier, can be generalized in such a manner that values assigned to the elements of the universal set fall within a specified range of unit interval $[0,1]$ and indicate the membership grade of these elements.

If $\mathrm{U}$ is a collection of objects denoted by $x$, then a fuzzy set $\overline{\mathrm{A}}$ in $\mathrm{U}$ is a set of ordered pair .....

$$
\overline{\mathrm{A}}=\left\{\left(x, \mu_{\overline{\mathrm{A}}}(x)\right) \mid x \in \mathrm{U}\right\}
$$

$\mu_{\bar{A}}(x)$ is called the membership function or grade of membership i.e. $\mu_{\bar{A}}: U \rightarrow[0,1]$. In this case, each membership function maps elements of an universal set $U$ into real numbers in $[0,1]$. Each fuzzy set is completely uniquely defined by one particular membership function; so the symbols of membership functions may also be used as labels of associated fuzzy sets. 

function.

In this text, we will use $\bar{A}$ as a fuzzy set and $\mu_{\bar{A}}$ as its membership

Example:4.1. ${ }^{[2]}$ Let us consider $\mathrm{U}=\{u, v, w, x, y, z\}$ and $\mu_{\bar{A}}: U \rightarrow$ $[0,1]$ defined by $\mu_{\bar{A}}(u)=0, \mu_{\bar{A}}(v)=0.2$, $\mu_{\bar{A}}(w)=0.6, \mu_{\bar{A}}(x)$ $=0.8, \mu_{\bar{A}}(y)=0.45$ and $\mu_{\bar{A}}(z)=1$. Then the fuzzy set $\bar{A}$ can be written as :---

$$
\bar{A}=\{(u, 0),(v, 0.2),(w, 0.6),(x, 0.8),(y, 0.45),(z, 1)\} .
$$

Example:4.2. Let us consider a fuzzy set $\bar{A}=$ "real numbers close to $5 "$ (see Figure 1)

Here $\overline{\mathrm{A}}=\{(x, \mu \overline{\mathrm{A}}(x)) \mid x \in \mathrm{U}\}, \mathrm{U}$ is the universal set, where the membership function is $\mu \overline{\mathrm{A}}(x)=1+\left(\mathrm{x}-5^{2}\right)^{-1}$.



Figure 1

Thus, a fuzzy set is denoted by an ordered pairs, the first element of which denotes the element and the second the degree of membership.

Example: 4.3. Let $U$ be the set of all human beings i.e. universal set and let $\overline{\mathrm{A}}=\{(x \in \mathrm{U} \mid x$ is weighty $\}$. Then $\overline{\mathrm{A}}$ is a "fuzzy set" because the property "weighty" is not well defined and can't be precisely measured as for a person who weighs $58 \mathrm{~kg}$., it is not clear whether he belongs to the set $\bar{A}$ or not.

For the time being, we may describe the concept "weighty" person by the curve shown in Figure 2, using common sense, where the only persons who are considered to be absolute "weighty" are those, whose weights are $120 \mathrm{~kg}$. or more and the persons who are considered to be not absolute "weighty" or of "zero weight" are those new borns (approx.). For example, a person with $50 \mathrm{~kg}$. of weight is considered to be "weighty" with "degree 0.5 " and at the same time also not "weighty" with "degree 0.5" according to the measuring curve we have used in 
Figure 2. We can't exclude this person from the set $\bar{A}$, nor include him completely .

Moreover, the two concepts are conflicting; $x$ is "weighty" or not "weighty" at the same time, which classcal mathematics can't accept. Such a vague and conflicting description of a set is acceptable by fuzzy mathematics, however, which turns out to be very useful in many realworld applications.

Here, the curve, introduced in Figure 2, can be used to define the partial membership of weight of any person related to set $\bar{A}$. Here, $\bar{A}$ $=\left\{\left(x, \mu_{\bar{A}}(x)\right) \mid x \in \mathrm{U}\right\}$

Where the membership function is $\mu_{\bar{A}}(x)=\left\{\begin{array}{cc}0, & \text { if } x \leq 0 \\ 1-\mathrm{e}^{-x}, & \text { if } x>0\end{array}\right.$



Figure 2

Example: 4.4. Let us now consider, as another simple example, three fuzzy sets defined within a finite universal set that consists of eight levels of effects of CORONA VIRUSES on human beings.

0 - No symptoms

1 - Mild fever and cough.

2 - Tiredness, tastelessness and loss of smell.

3 - Home isolation is required with proper medication.

4 - Difficulties in breathing, throat problem.

5 - Hospitalization is required.

6 - Under ventilation.

7 - Death. 
Membership functions of three fuzzy sets, which attempt to capture the concepts of little-effected, highly- effected, very seriously effected persons are defined in Figure 3. by three colors.

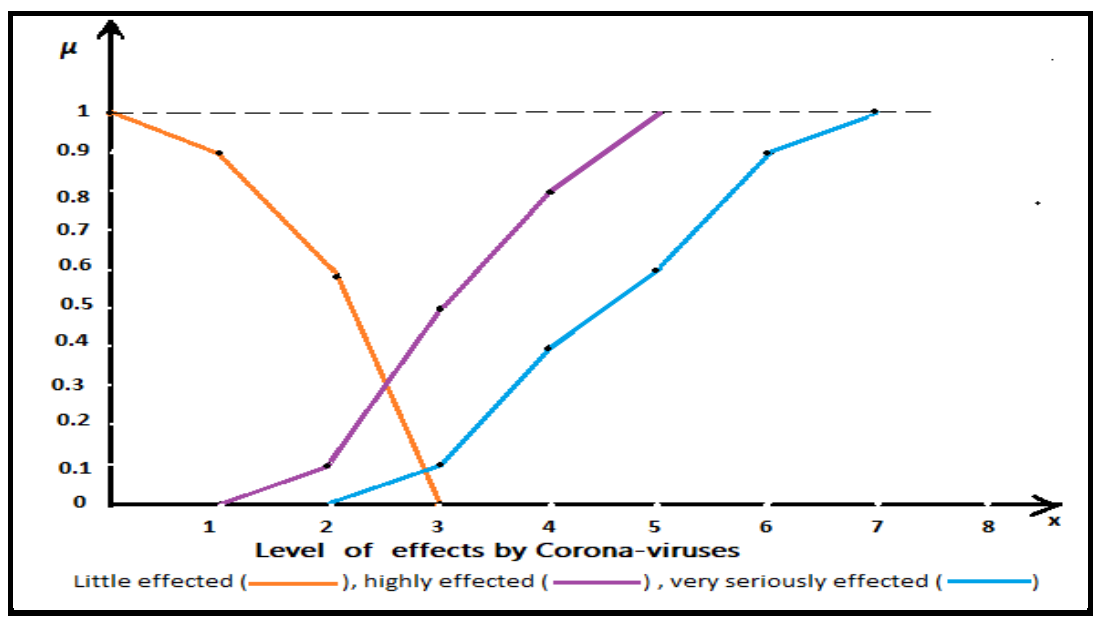

Figure 3

Example: 4.5. Several fuzzy sets representing the concepts like very low, low, medium, high, very high and so on are often used to define different states of a variable. Such a variable is generally called a fuzzy variable. In Figure 4, number of passengers, in a compartment of a train, within a range $\left[\mathrm{P}_{1}, \mathrm{P}_{2}\right]$ is characterized as a fuzzy variable. They are all defined by the membership functions of the form.....

$\left[\mathrm{P}_{1}, \mathrm{P}_{2}\right] \rightarrow[0,1]$. Graphs of these functions have trapezoidal shapes.

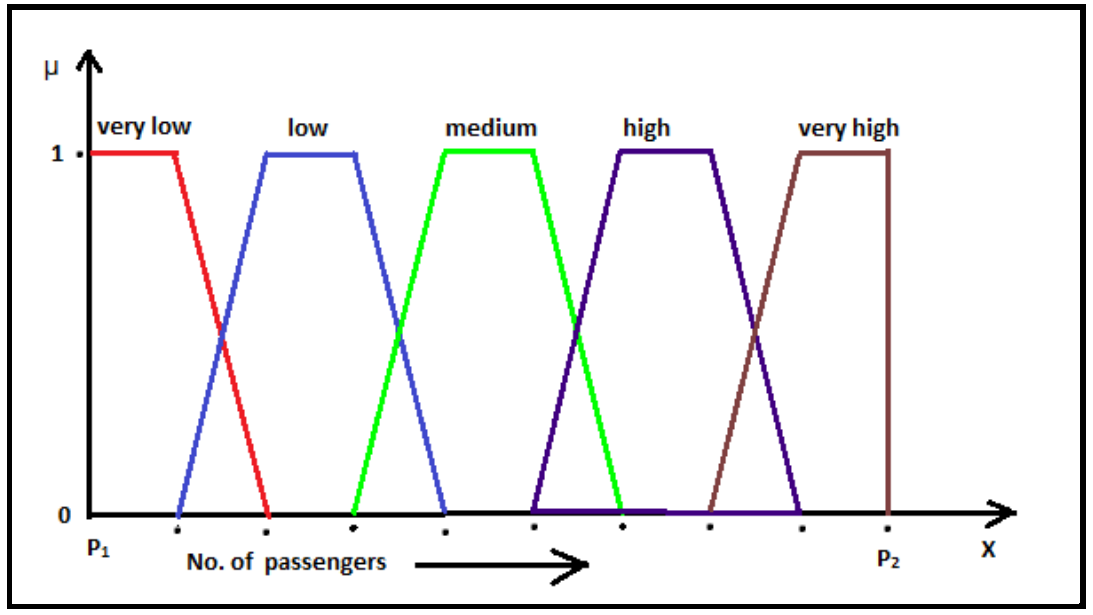

Figure 4 
The significance of fuzzy variables is that they facilitate gradual transitions between states and possesses a natural capability to express and deal with observation and measurement uncertainties, but its usefulness depends critically on our capability to construct appropriate membership functions for various given concepts in various contexts.

\section{SOME BASIC CONCEPTS OF FUZZY SETS}

Now, we want to discuss some basic concepts of fuzzy sets. To illustrate the concepts, we consider three fuzzy sets that represent the concepts of a weak, mediocre and good students in a class. A reasonable mathematical expression of these concepts by trapezoidal membership functions $\mu_{\overline{\mathrm{A}} 1}, \mu_{\overline{\mathrm{A}} 2}$ and $\mu_{\overline{\mathrm{A}} 3}$ is shown in Figure 5. These functions are defined on the the interval $[0,100]$ as follows:

$$
\begin{aligned}
& \mu_{\bar{A} 1}(x)= \begin{cases}1 & \text { if } x \leq 25 \\
(40-x) / 15 & \text { if } 25<x<40 \\
0 & \text { if } x \geq 40\end{cases} \\
& \mu_{\bar{A} 2}(x)= \begin{cases}0 & \text { if } x \leq 25 \text { or } x \geq 75 \\
(x-25) / 15 & \text { if } 25<x<40 \\
1 & \text { if } 40 \leq x \leq 60 \\
(70-x) / 15 & \text { if } 60<x<75\end{cases} \\
& \mu_{\bar{A} 3}(x)= \begin{cases}0 & \text { if } x \leq 60 \\
(x-60) / 15 & \text { if } 60<x<75 \\
1 & \text { if } x \geq 75,\end{cases}
\end{aligned}
$$

Here, by x we denote $\%$ of marks obtained by a student.

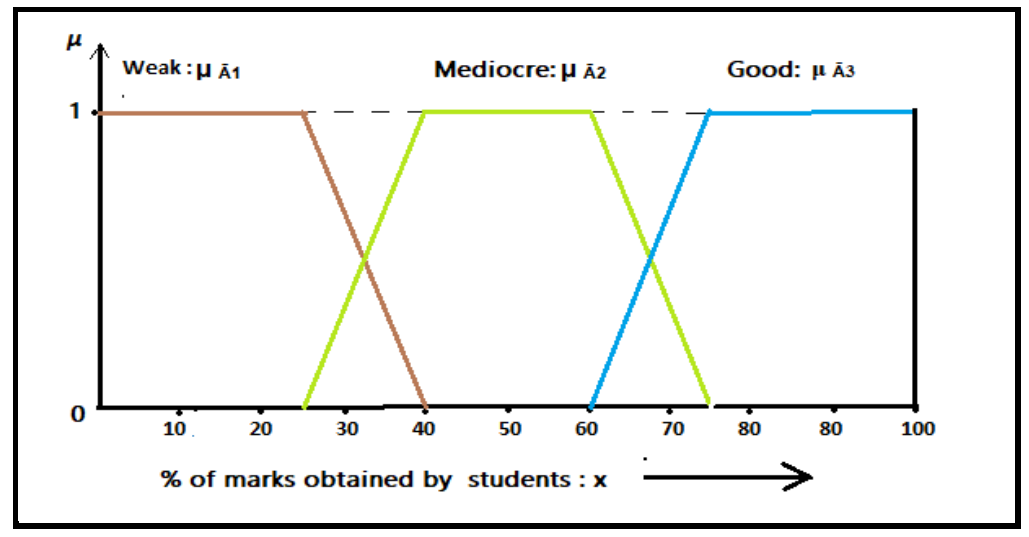

Figure 5 
Definition (1): The two subsets ${ }^{\alpha} \overline{\mathrm{A}}$ and ${ }^{\alpha+} \overline{\mathrm{A}}$, of $\overline{\mathrm{A}}$ defined by

$$
\begin{array}{cc}
\alpha \bar{A}=\left\{x \in \bar{A} \mid \mu_{\bar{A}}(x) \geq \alpha\right\} & \alpha \in(0,1] \\
\text { and }{ }^{\alpha+} \bar{A}=\left\{x \in \bar{A} \mid \mu_{\bar{A}}(x)>\alpha\right\} & \alpha \in[0,1)
\end{array}
$$

are called " $\alpha$-cut set" or " $\alpha$-level set" and the "strong $\alpha$-cut set" or "strong $\alpha$-level set", respectively. The corresponding characteristic function of $\alpha$-level set can be represented as follows:

$$
\text { And } \left.\quad \begin{array}{c}
\chi_{\alpha \bar{A}}(x)=\left\{\begin{array}{ll}
1, & \text { for } \left.x \in^{\alpha} \bar{A} \text { (i.e. } \mu_{\bar{A}}(x) \geq \alpha\right) \\
0, & \text { for } x \notin^{\alpha} \bar{A}\left(\text { i.e. } \mu_{\bar{A}}(x)<\alpha\right)
\end{array}\right\} \\
\quad \chi_{\alpha+\bar{A}}(x)=\left\{\begin{array}{ll}
1, & \text { for } x \in^{\alpha+} \bar{A}\left(\text { i.e. } \mu_{\bar{A}}(x)>\alpha\right) \\
0, & \text { for } x \notin^{\alpha+} \bar{A}\left(\text { i.e. } \mu_{\bar{A}}(x) \leq \alpha\right)
\end{array}\right\}
\end{array}\right\}
$$

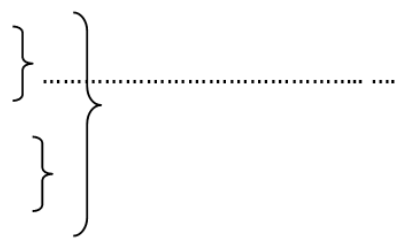

Example: 5.1. Now, we refer to Example:4.1[2] and try to make a list of possible $\alpha$-cut sets:

$$
\begin{aligned}
& .2 \bar{A}=\{\mathrm{v}, \mathrm{w}, \mathrm{x}, \mathrm{y}, \mathrm{z}\} \\
& { }^{45} \overline{\mathrm{A}}=\{\mathrm{w}, \mathrm{x}, \mathrm{y}, \mathrm{z}\} \\
& { }^{6} \overline{\mathrm{A}}=\{\mathrm{w}, \mathrm{x}, \mathrm{z}\} \\
& { }_{1} \overline{\mathrm{A}}=\{\mathrm{z}\}
\end{aligned}
$$

The strong $\alpha$-cut set for $\alpha=.8$ is ${ }^{8+} \bar{A}=\{z\}$.

Definition(2): A fuzzy set is convex iff its every $\alpha$-cut subset is convex i.e. for any $\mathrm{x}_{1}, \mathrm{x}_{2} \in \mathrm{U}$ and any $\lambda \in[0,1]$ we have

$$
\mu_{\bar{A}}\left(\lambda x_{1}+(1-\lambda) x_{2}\right) \geq \min .\left\{\mu_{\bar{A}}\left(x_{1}\right), \mu_{\bar{A}}\left(x_{2}\right)\right\} \text {. }
$$

It must be very clear that the definition of convexity for fuzzy sets does not mean that the membership function of a convex fuzzy set is a convex function. Actually, those are concave and not convex, according to standard definitions.

Theorem 5.1: A "strong $\alpha$-cut subset" of a fuzzy set $\bar{A}$ is convex if its " $\alpha$-cut subset" is convex.

Proof: Proof is very obvious from definition.

Definition (3): Union and intersection of two fuzzy sets:

Given two fuzzy sets $\overline{\mathrm{A}}$ and $\dot{\mathrm{B}}$, their standard union $\overline{\mathrm{O}}=\overline{\mathrm{A}} \cup \dot{\mathrm{B}}$ is pointwise defined by

$$
\boldsymbol{\mu}_{\bar{O}}(x)=\max \left\{\boldsymbol{\mu}_{\bar{A}}(x), \boldsymbol{\mu} \dot{\mathrm{B}}(x)\right\}, \mathrm{x} \in \mathrm{U} \text {. }
$$

Given two fuzzy sets $\bar{A}$ and $\mathrm{B}^{-}$, their standard intersection $\overline{\mathrm{E}}=\overline{\mathrm{A}} \cap$ $B$ is pointwise defined by

$$
\boldsymbol{\mu}_{\overline{\mathrm{E}}}(x)=\min \left\{\mu_{\overline{\mathrm{A}}}(x), \mu_{\mathrm{B}}(x)\right\}, x \in U .
$$

where max and min are the maximum and minimum operator, respectively. 
Definition(4): Complement of a set and the equilibrium point:

The membership function of the standard complement $c \bar{A}$ of a fuzzy set $\overline{\mathrm{A}}$, is defined by

$\boldsymbol{\mu}_{c \bar{A}}(x)=1--\boldsymbol{\mu}_{\bar{A}}(x), x \in U$. [ In this text, we will use c $\bar{A}$ as a complement set of a fuzzy set $\bar{A}$.]

The equilibrium of a complement $c$ is that degree of membership in a fuzzy set $\bar{A}$ which is equal to the degree of membership in complement $c \bar{A}$ i.e. which is a solution of the equation $1-\mathrm{x}=\mathrm{x}, \forall \mathrm{x} \epsilon$ $\boldsymbol{\mu}_{\bar{A}}(x)$.

Properties [3] of fuzzy complements: Function c, the fuzzy complement may satisfy following axiomatic properties:

Axiom 5.1: If $\mathrm{a} \leq \mathrm{b}$, then $\mathrm{c}(\mathrm{a})=\mathrm{c}(\mathrm{b}), \forall \mathrm{a}, \mathrm{b} \in[0,1]$. (Monotonicity)

Axiom 5.2: c $(0)=1, \mathrm{c}(1)=0$. (Boundary conditions)

Axiom 5.3: $\mathrm{c}$ is a continuous function.

Axiom 5.4: $\mathrm{c}$ is involutive i.e. $\mathrm{c}(\mathrm{c}(\mathrm{x}))=\mathrm{x}, \forall \mathrm{x} \in[0,1]$.

Definition(5) : Cartesian product :

The cartesian product of $\mathrm{n}$ fuzzy sets $\overline{\mathrm{A}}_{1}, \ldots \ldots \ldots \ldots \ldots, \ldots \ldots, \overline{\mathrm{A}}_{\mathrm{n}}$ in $\mathrm{U}_{1}$, .............., $U_{\mathrm{n}}$ is a fuzzy set in the product space $\mathrm{U}_{1} \mathrm{x} . . . . . . \times \mathrm{x} \mathrm{U}_{\mathrm{n}}$ with the membership function

$$
\boldsymbol{\mu}\left(\bar{A}_{1} \times \ldots \times \bar{A}_{n}\right)(x)=\min _{\mathbf{i}}\left\{\boldsymbol{\mu}_{\bar{A} \mathrm{i}}\left(x_{i}\right) \mid \mathrm{x}=\left(\mathrm{x}_{1}, \mathrm{x}_{2} \ldots \ldots \ldots \mathrm{x}_{\mathrm{n}}\right), \mathrm{x}_{\mathrm{i}} \in \mathrm{U}_{\mathrm{i}}\right\}
$$

Example:5.2. Now, we refer to Example:4.1[2] where $\bar{A}=\{(u, 0)$, $(v, 0.2),(w, 0.6),(x, 0.8),(y, 0.45),(z, 1)\}$.

And assume $\bar{B}=\{(w, 0.2),(x, 0.4),(y, 0.48),(z, 0.9),(m, 1),(n, 1)$.

Then union , $\overline{0}=\{(\mathrm{u}, 0),(\mathrm{v}, 0.2),(\mathrm{w}, 0.6),(\mathrm{x}, 0.8),(\mathrm{y}, 0.48),(\mathrm{z}, 1)$, $(\mathrm{m}, 1),(\mathrm{n}, 1)\}$.

Intersection , $\overline{\mathrm{E}}=\{(\mathrm{w}, 0.2),(\mathrm{x}, 0.4),(\mathrm{y}, 0.45),(\mathrm{z}, 0.9)\}$

Complement, $c \bar{B}=\{(\mathrm{u}, 1),(\mathrm{v}, 1),(\mathrm{w}, 0.8),(\mathrm{x}, 0.6),(\mathrm{y}, 0.72),(\mathrm{z}, 0.1)\}$.

Example:5.3. Let $\bar{A}(x)=\{(a, 0.3),(b, 1),(c, 0.8),(d, 0.6)\}$ and $\bar{B}(x)$ $=\{(\mathrm{a}, 1),(\mathrm{c}, 0.6)\}$

Then $\bar{A} \times \bar{B}=\{[(a ; a), 0.3],[(b ; a), 1],[(c ; a), 0.8],[(d ; a), 0.6],[(a ; c)$, $0.3],[(b ; c), 0.6],[(c ; c), 0.6],[(d ; c), 0.6]\}$.

where $a, b, c, d \in U$. 
Definition(6) : Let $G$ be a group. A fuzzy subset $\bar{A}$ of the group $G$ is called a fuzzy subgroup of the group $G$ if

$$
\begin{aligned}
& \mu_{\bar{A}}(x y) \geq \min \left\{\mu_{\bar{A}}(x), \mu_{\bar{A}}(y)\right\}, \quad \forall x, y \in G . \\
& \mu_{\bar{A}}\left(x^{-1}\right)=\mu_{\bar{A}}(x), \quad \forall x \in G
\end{aligned}
$$

Definition(7): Fuzzy union of two fuzzy sets $\overline{\mathrm{A}}_{1}$ and $\overline{\mathrm{A}}_{2}$ :

Let $\bar{A}_{1}$ be a fuzzy subset of a set $X_{1}$ and $\bar{A}_{2}$ be a fuzzy subset of a set $\mathrm{X}_{2}$. Then the fuzzy union of the fuzzy sets $\overline{\mathrm{A}}_{1}$ and $\overline{\mathrm{A}}_{2}$ is defined as follows :.....

$$
\begin{aligned}
& \mu_{\overline{\mathrm{A}} 1} \cup \mu_{\overline{\mathrm{A}} 2}: \mathrm{X}_{1} \cup \mathrm{X}_{2} \rightarrow[0,1] \quad \text { given by } \\
& \left(\mu_{\overline{\mathrm{A}} 1} \cup \mu_{\bar{A}_{2}}\right)(\mathrm{x})=\left\{\begin{array}{cc}
\max \left(\mu_{\overline{\mathrm{A}} 1}(x), \mu_{\overline{\mathrm{A}} 2}(x)\right) & \text { when } \mathrm{x} \in \mathrm{X}_{1} \cap \mathrm{X}_{2} \\
\mu_{\overline{\mathrm{A}} 1}(\mathrm{x}) & \text { when } \mathrm{x} \in \mathrm{X}_{1} \text { and } \mathrm{x} \notin \mathrm{X}_{2} \\
\mu_{\overline{\mathrm{A}} 2}(\mathrm{x}) & \text { when } \mathrm{x} \in \mathrm{X}_{2} \text { and } \mathrm{x} \notin \mathrm{X}_{1}
\end{array}\right.
\end{aligned}
$$

Example:5.4. Let $\mathrm{X}_{1}=\{\mathrm{a}, \mathrm{b}, \mathrm{c}, \mathrm{d}, \mathrm{e}\}$ and $\mathrm{X}_{2}=\{\mathrm{b}, \mathrm{d}, \mathrm{f}, \mathrm{h}, \mathrm{j}\}$ be two sets .

Let us define $\mu_{\overline{\mathrm{A}} 1}: \mathrm{X}_{1} \rightarrow[0,1]$ by $\mu_{\overline{\mathrm{A}} 1}(\mathrm{x})=$

$$
\begin{cases}1, & \text { if } x=a, b \\ 0.7, & \text { if } x=c \\ 0.16, & \text { if } x=d, e\end{cases}
$$

And define $\mu_{\overline{\mathrm{A}} 2}: \mathrm{X}_{2} \rightarrow[0,1]$ by $\mu_{\overline{\mathrm{A}} 2}(\mathrm{x})=\left\{\begin{array}{c}1, \text { if } \mathrm{x}=\mathrm{b}, \mathrm{d} . \\ 0.7, \text { if } \mathrm{x}=\mathrm{f} \\ 0.16, \text { if } \mathrm{x}=\mathrm{h}, \mathrm{j} .\end{array}\right.$

Now it is easy to calculate $\mu_{\overline{\mathrm{A}} 1} \cup \mu_{\overline{\mathrm{A}} 2}$ as follows.................

$$
\left(\mu_{\bar{A} 1} \cup \mu_{\bar{A} 2}\right)(x)=\left\{\begin{aligned}
1, & \text { if } x=a, b, d \\
0.7, & \text { if } x=c, f \\
0.16, & \text { if } x=e, h, j .
\end{aligned}\right.
$$

Definition(8): Fuzzy union of three fuzzy sets $\overline{\mathrm{A}}_{1}, \overline{\mathrm{A}}_{2}$ and $\overline{\mathrm{A}}_{3 \text { : }}$

Let $\bar{A}_{1}$ be a fuzzy subset of a set $X_{1}, \bar{A}_{2}$ be a fuzzy subset of a set $X_{2}$ and $\bar{A}_{3}$ be a fuzzy subset of a set $X_{3}$. Then the fuzzy union of the fuzzy sets $\bar{A}_{1}, \bar{A}_{2}$ and $\bar{A}_{3}$ is defined as follows :...... 


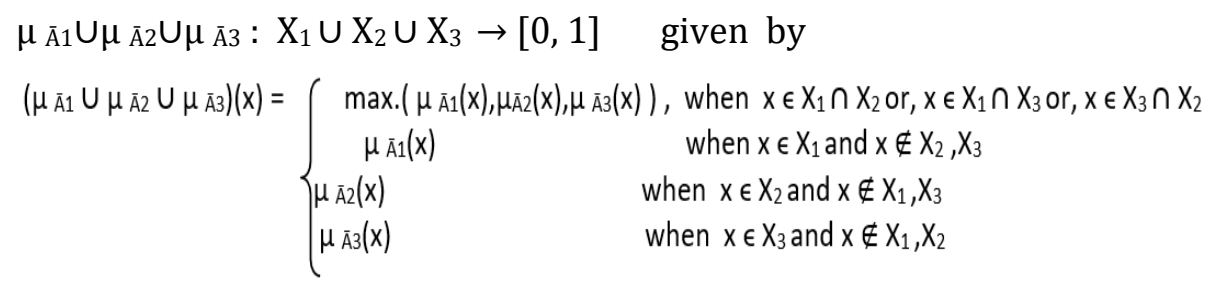

Example:5.6. Let $\mathrm{X}_{1}=\{\mathrm{a}, \mathrm{b}, \mathrm{c}, \mathrm{d}, \mathrm{e}\}, \mathrm{X}_{2}=\{\mathrm{b}, \mathrm{d}, \mathrm{f}, \mathrm{h}, \mathrm{j}\}$ and $\mathrm{X}_{3}=\{\mathrm{a}$, c, e, $g$, i \} be three sets .

Let us define $\mu_{\overline{\mathrm{A}} 1}: \mathrm{X}_{1} \rightarrow[0,1]$ by $\mu_{\overline{\mathrm{A}} 1}(\mathrm{x})=\left\{\begin{array}{l}1, \text { if } \mathrm{x}=\mathrm{a}, \mathrm{b} \\ 0.7, \text { if } \mathrm{x}=\mathrm{c} \\ 0.16, \text { if } \mathrm{x}=\mathrm{d}, \mathrm{e}\end{array}\right.$ and define $\mu_{\bar{A} 2}: X_{2} \rightarrow[0,1]$ by $\mu_{\bar{A} 2}(x)=\left\{\begin{array}{l}1, \text { if } x=b, d . \\ 0.7, \text { if } x=f \\ 0.16, \text { if } x=h, j .\end{array}\right.$ and define $\mu_{\bar{A} 3}: X_{3} \rightarrow[0,1]$ by $\mu_{\bar{A} 2}(x)= \begin{cases}1, & \text { if } x=a \\ 0.7, & \text { if } x=c, e . \\ 0.16, & \text { if } x=g, i .\end{cases}$ Now it is easy to calculate $\mu_{\overline{\mathrm{A}} 1} \cup \mu_{\overline{\mathrm{A}} 2} \cup \mu_{\overline{\mathrm{A}} 3}$ as follows

$$
\left(\mu_{\bar{A} 1} \cup \mu_{\bar{A} 2} \cup \mu_{\bar{A} 3}\right)(x)=\left\{\begin{array}{c}
1, \text { if } x=a, b, d \\
0.7, \text { if } x=c, e, f \\
0.16, \text { if } x=g, h, i, j
\end{array}\right.
$$

Theorem 5.2: ${ }^{\alpha+}(\mathrm{c} \overline{\mathrm{A}})={ }^{(1-\alpha)}(\mathrm{c} \overline{\mathrm{A}})$

Proof: Let $x \in^{\alpha+}(\mathrm{c} \overline{\mathrm{A}})$, which implies that $\mathrm{x} \notin{ }^{\alpha+}(\overline{\mathrm{A}})$

Hence $\overline{\mathrm{A}}(\mathrm{x}) \leq \alpha, \Rightarrow 1-\overline{\mathrm{A}}(\mathrm{x}) \geq 1-\alpha$ i.e. $\quad \mathrm{c} \overline{\mathrm{A}}(\mathrm{x}) \geq 1-\alpha$, which means that $x \in \in^{1-\alpha}(c \bar{A})$.

Consequently, ${ }^{\alpha+}(\mathrm{c} \overline{\mathrm{A}}) \subseteq(1-\alpha)(\mathrm{c} \overline{\mathrm{A}})$

Conversely, for any y $\epsilon^{(1-\alpha)}(\mathrm{c} \overline{\mathrm{A}})$, we have y $\notin^{1-\alpha}(\overline{\mathrm{A}})$

Hence $\bar{A}(\mathrm{y})<1-\alpha$ and $1-\bar{A}(\mathrm{y})>\alpha$ i.e. $c \bar{A}(\mathrm{y})>\alpha$, which means that $y \in{ }^{\alpha+}(\mathrm{c} \overline{\mathrm{A}})$ i.e. ${ }^{(1-\alpha)}(\mathrm{c} \overline{\mathrm{A}}) \subseteq{ }^{\alpha+}(\mathrm{c} \overline{\mathrm{A}})$.

Therefore, ${ }^{\alpha+}(\mathrm{c} \overline{\mathrm{A}})={ }^{(1-\alpha)}(\mathrm{c} \overline{\mathrm{A}})$. 
We now want to introduce a special fuzzy set, $\alpha\left({ }^{\alpha} \overline{\mathrm{A}}\right)$, by defining as...

$\alpha\left({ }^{\alpha} \overline{\mathrm{A}}\right)=\left\{\mathrm{x} \in \overline{\mathrm{A}} \mid \mu_{\alpha(\alpha \overline{\mathrm{A}})}(\mathrm{x})=\alpha \Lambda \boldsymbol{\chi}_{\alpha \overline{\mathrm{A}}}(x)\right\}, \boldsymbol{\chi}_{\alpha \overline{\mathrm{A}}}(x)$ is defined by equation ... “(1)".

Theorem 5.3: $\cap \alpha\left({ }^{\alpha} \bar{A}\right)(x)=0$.

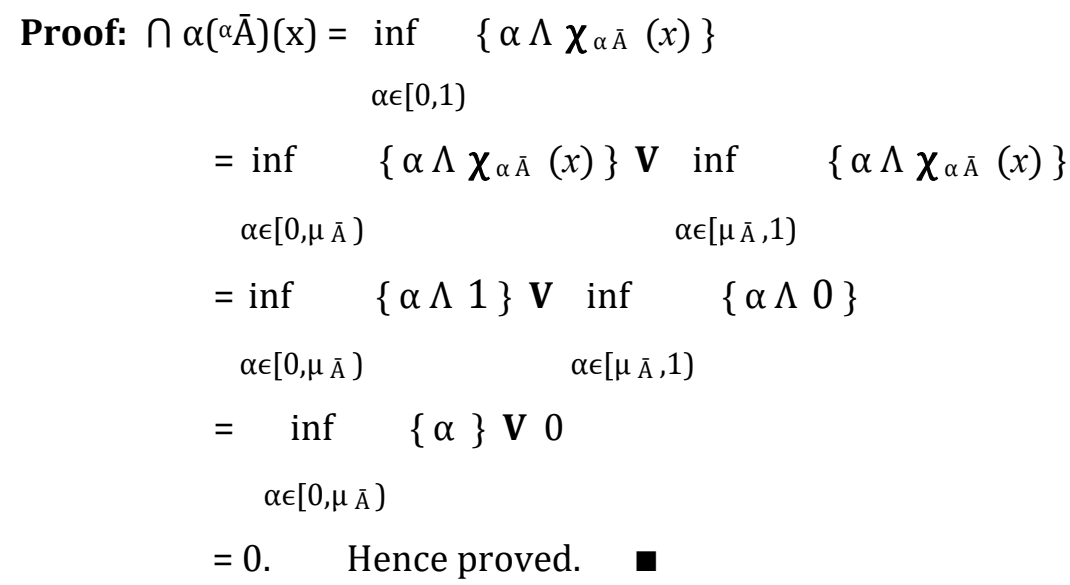

Theorem 5.4: $\cap \alpha(\alpha+\bar{A})(x)=0$.

Proof: Here, proof is similar to that of previous Theorem , so left for the readers.

Definition(9): Here we introduce a class of fuzzy complements defined by

$$
\mathrm{c}_{\lambda}(\mathrm{a})=\frac{2-2 a}{\lambda a+2}, \text { where } \lambda \in(-2, \infty), \forall \mathrm{a} \in[0,1]
$$

This class of functions of fuzzy complements satisfies all the axioms given in properties [3]. For different

values of parameter $\lambda$, we obtain different involutive fuzzy complement. This class may be illustrated for different values of $\lambda$ as in Figure 6. For $\lambda=0$, the function becomes the classical complement i.e. $\mathrm{a}=1-\mathrm{a}, \quad \forall \mathrm{a} \in[0,1]$. Let us name this as the $\underline{\text { S.B's. class of fuzzy }}$ complements.

For any fuzzy complement $\mathrm{c}$, the increasing generators are $\mathrm{g}(\mathrm{a})=$ a where $g$ is a continuous function from $[0,1]$ to $\mathbb{R}$ such that $g(0)=0, g$ is strictly increasing and $\mathrm{c}(\mathrm{a})=\mathrm{g}^{-1}(\mathrm{~g}(1)-\mathrm{g}(\mathrm{a})) \forall \mathrm{a} \in[0,1]$.

For the S.Bs. class of fuzzy complements, the increasing generators are .............. 


$$
g_{\lambda}(a)=\frac{1}{\lambda / 2} \ln \left(1+\frac{\lambda}{2} a\right) \text { for if we take.... }
$$

$$
\lim _{\lambda \rightarrow 0} g_{\lambda}(a)=a, \lambda>--2
$$

Interestingly, if we take a class of two parameter increasing generators

$g_{\lambda, \omega}(a)=\frac{1}{\lambda / 2} \ln \left(1+\frac{\lambda}{2} a^{\omega}\right)$ for $\lambda>--2$ and $\omega>0$, we obtain a class of fuzzy complements

$\mathrm{c}_{\lambda, \omega}(\mathrm{a})=\left[\left(1-\mathrm{a}^{\omega}\right) /\left(1+\frac{\lambda}{2} \mathrm{a}^{\omega}\right)\right]^{1 / \omega}$ which contains the S.B's class ( for $\omega=1$ ) and the Yager class ( for $\lambda=0$ ) as well.

Again, if there exists a continuous function $\mathrm{f}$ from $[0,1]$ to $\mathbb{R}$ such that $f(1)=0$, f is strictly decreasing and $c(a)=f^{-1}(f(0)-f(a)) \forall a \in[0$, 1 ], where $\mathrm{c}$ is a fuzzy complement then $\mathrm{f}$ is a decreasing generator. Here

$$
g(a)=f(0)-f(a)
$$

For the S.Bs. class, if we take $\mathrm{f}(\mathrm{a})=--\frac{2}{\lambda} \ln \left(\frac{2+\lambda a}{2+\lambda}\right)$, then $\mathrm{f}$ is a decreasing function, $f(1)=0$ and f satisfies the relation $g(a)=f(0)-f(a)$.

[ since, $f(0)=--\frac{2}{\lambda} \ln \left(\frac{2}{2+\lambda}\right)$, so , -- $\frac{2}{\lambda} \ln \left(\frac{2}{2+\lambda}\right)-\left\{-\frac{2}{\lambda} \ln \left(\frac{2+\lambda a}{2+\lambda}\right)\right\}=$ $\left.\frac{1}{\lambda / 2} \ln \left(1+\frac{\lambda}{2} a\right)=g(a).\right]$

Therefore, here $\mathrm{f}(\mathrm{a})=--\frac{2}{\lambda} \ln \left(\frac{2+\lambda a}{2+\lambda}\right)$ is a decreasing generator .

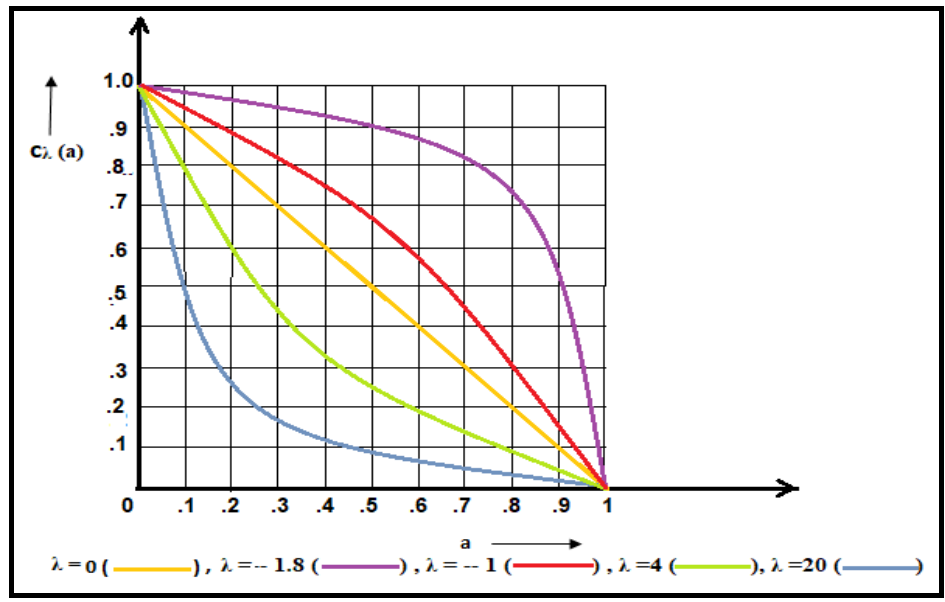

Figure 6 


\section{SOME ARITHMETIC OPERATIONS ON INTERVALS}

Here, we are concern about the situation where the value of a member $x$ of a set is uncertain. We assume, that the information on the uncertain value of $x$ provides an acceptable range $a \leq x \leq b$, where $[a, b] \subset R$, is called the interval of confidence about the value $x$. We mainly study closed and bounded intervals in this text, unless otherwise stated.

Definition(10): Distance and width:

Let $A=\left[a_{1}, a_{2}\right]$ and $B=\left[b_{1}, b_{2}\right]$ be intervals. Then distance between $A$ and $B$ is defined by

$$
\mathrm{d}(\mathrm{A}, \mathrm{B})=\max \left\{\left|\mathrm{a}_{1}-\mathrm{b}_{1}\right|,\left|\mathrm{a}_{2}-\mathrm{b}_{2}\right|\right\} \text {. }
$$

The width of an interval $\mathrm{A}=\left[\mathrm{a}_{1}, \mathrm{a}_{2}\right]$ may be defined as $\mathrm{w}\{\mathrm{A}\}=\mathrm{w}\{$ $\left.\left[\mathrm{a}_{1}, \mathrm{a}_{2}\right]\right\}=\mathrm{a}_{2}-\mathrm{a}_{1}$.

or equivalently[4] $\mathrm{w}\{\mathrm{A}\}=\max \left|\mathrm{x}_{1}-\mathrm{x}_{2}\right|$

$\mathrm{x}_{1}, \mathrm{x}_{2} \in \mathrm{A}$

Theorem 6.1: Let $A=\left[a_{1}, a_{2}\right], B=\left[b_{1}, b_{2}\right], C=\left[c_{1}, c_{2}\right]$ be the intervals. Then

i) $d(A+B, C+B)=d(A, C)$.

ii) $d(A-B, A-C)=d(B, C)$.

iii) iii) $|d(A, C)-d(B, C)| \leq d(A, B)$.

\section{Proof:}

i) $d(A+B, C+B)=\max \left\{\left|\left(a_{1}+b_{1}\right)-\left(c_{1}+b_{1}\right)\right|,\left|\left(a_{2}+b_{2}\right)-\left(c_{2}+b_{2}\right)\right|\right\}$

$=\max \left\{\mid\left(a_{1}-c_{1}||,\left(a_{2}-c_{2} \mid\right\}=d(A, C)\right.\right.$.

ii) $d(A-B, A-C)=\max \left\{\left|\left(a_{1}-b_{1}\right)-\left(a_{1}-c_{1}\right)\right|,\left|\left(a_{2}-b_{2}\right)-\left(a_{2}-c_{2}\right)\right|\right\}$.

$$
=\max \left\{\left|\left(c_{1}-b_{1}\right)\right|,\left|\left(c_{2}-b_{2}\right)\right|\right\}=d(C, B)=d(B, C) .
$$

iii) From triangular law of addition, we have $d(A, C) \leq d(A, B)+d(B, C)$

$$
\begin{aligned}
& \text { By transposing, we have } d(A, C)-d(B, C) \leq d(A, B) \text {. } \\
& \text { Similarly, } \quad d(B, C)-d(A, C) \leq d(B, A) \text {. } \\
& \text { Or , } d(A, C)-d(B, C) \geq-d(A, B) \\
& \text { By "(2)" and "(4)" we have, ... -- d( } A, B) \leq d(A, C)-d(B, C) \leq d(A, B) \text {. } \\
& \text { Hence, }|d(A, C)-d(B, C)| \leq d(A, B) \text {. }
\end{aligned}
$$

Theorem 6.2: Let $A=\left[a_{1}, a_{2}\right], B=\left[b_{1}, b_{2}\right], C=\left[c_{1}, c_{2}\right]$ be the intervals. Then $d(A B, C B) \leq|B| d(A, C)$

Proof: Here, for convenience, we use $l(A)=a_{1}$ and $u(A)=a_{2}$ for any interval $A=\left[a_{1}, a_{2}\right]$ in this proof only.

Now, we have to prove that max $\{|l(\mathrm{AB})-l(\mathrm{CB})|, \mid u(\mathrm{AB})-$ $u(\mathrm{CB}) \mid\} \leq|\mathrm{B}| \mathrm{d}(\mathrm{A}, \mathrm{C})$ 
First of all we are going to prove $|l(\mathrm{AB})-l(\mathrm{CB})| \leq|\mathrm{B}| \mathrm{d}(\mathrm{A}, \mathrm{C})$

Without loss of generality, let us assume that $l(\mathrm{AB}) \geq l(\mathrm{CB})$,

Then since $\mathrm{CB}=\{\mathrm{cb} \mid \mathrm{c} \in \mathrm{C}, \mathrm{b} \in \mathrm{B}\} \exists \mathrm{b} \in \mathrm{B}$ such that $l(\mathrm{CB})=l(\mathrm{Cb})$.

On the other hand, $\mathrm{bA} \subseteq \mathrm{AB} \Rightarrow$ that $l(\mathrm{bA}) \geq l(\mathrm{AB})$.

Hence, we have $l(\mathrm{bA})--l(\mathrm{Cb}) \geq l(\mathrm{AB})--l(\mathrm{CB}) \geq 0$

So that, $|l(\mathrm{AB})--l(\mathrm{CB})|=l(\mathrm{AB})--l(\mathrm{CB})$

$$
\begin{aligned}
& \leq l(\mathrm{bA})--l(\mathrm{Cb})=|l(\mathrm{bA})-l(\mathrm{Cb})| \\
& \leq|\mathrm{b}| \mathrm{d}(\mathrm{A}, \mathrm{C}) \\
& \leq|\mathrm{B}| \mathrm{d}(\mathrm{A}, \mathrm{C}) .
\end{aligned}
$$

In the similar manner, we can prove that $|u(\mathrm{AB})-u(\mathrm{CB})|\} \leq|\mathrm{B}|$ $d(A, C)$.

Hence, we can conclude that $\mathrm{d}(\mathrm{AB}, \mathrm{CB})=\max \{|l(\mathrm{AB})-l(\mathrm{CB})|$, $|u(\mathrm{AB})-u(\mathrm{CB})|\} \leq|\mathrm{B}| \mathrm{d}(\mathrm{A}, \mathrm{C})$.

Corollary: If the sets $\mathrm{X}, \mathrm{Y}, \mathrm{Z}, \mathrm{W} \in \mathrm{U}$, (where $\mathrm{U}$ is the universal set)

Then $|\mathrm{d}(X, Y)-d(Z, W)| \leq d(X, Z)+d(Y, W)$.

Proof: $|d(X, Y)-d(Z, W)| \leq|d(X, Y)-d(Y, Z)|+\mid d(Y, Z)-d(Z$, $W) \mid \leq d(X, Z)+d(Y, W)$.

Theorem 6.3: Let $X$ and $Y$ be any two intervals. Then......

(i) $\mathrm{w}\{\mathrm{XY}\} \geq \mathrm{w}\{\mathrm{X}\}|\mathrm{Y}|--|\mathrm{X}| \mathrm{w}\{\mathrm{Y}\}$ and $\mathrm{w}\{\mathrm{XY}\} \geq|\mathrm{X}| \mathrm{w}\{\mathrm{Y}\} \quad-$ $\mathrm{w}\{\mathrm{X}\}|\mathrm{Y}|$.

(ii) $\frac{\mathrm{w}\{\mathrm{XY}\}}{1+\mathrm{w}\{\mathrm{XY}\}} \leq \frac{\mathrm{w}\{\mathrm{X}\}|\mathrm{Y}|}{1+\mathrm{w}\{\mathrm{X}\}|\mathrm{Y}|}+\frac{|\mathrm{X}| \mathrm{w}\{\mathrm{Y}\}}{1+|\mathrm{X}| \mathrm{w}\{\mathrm{Y}\}}$.

Proof:

$$
\begin{aligned}
& \text { i)we have } w\{X Y\}=\max _{x_{1}, X_{2} \in X ; y_{1}, y_{2} \in Y}\left|x_{1} y_{1}-x_{2} y_{2}\right| \quad \text { [we use equivalent }{ }^{[4]} \text { definition here.] } \\
& =\max _{x_{1}, x_{2} \in X ; y_{1}, y_{2} \in Y}\left|x_{1} y_{1}-x_{1} y_{2}+x_{1} y_{2}--x_{2} y_{2}\right| \\
& \geq \max _{\mathrm{x}_{1}, \mathrm{x}_{2} \in X_{;} \mathrm{y}_{1}, \mathrm{y}_{2} \in \mathrm{Y}}\left\{\left|\mathrm{x}_{1}\left(\mathrm{y}_{1}-\mathrm{y}_{2}\right)\right|--\left|\mathrm{y}_{2}\left(\mathrm{x}_{2}-\mathrm{x}_{1}\right)\right|\right\} \\
& \geq \max _{x_{1}, x_{2} \in X ; y_{1}, y_{2} \in Y}\left|x_{1}\right|\left|\left(y_{1}-y_{2}\right)\right|-\max _{x_{1}, x_{2} \in X ; y_{1}, y_{2} \in Y}\left|y_{2}\right|\left|\left(x_{2}-x_{1}\right)\right| \\
& =\max _{\mathrm{x}_{1}, \mathrm{x}_{2} \in X ; \mathrm{y}_{1}, \mathrm{y}_{2} \in Y}\left|\mathrm{x}_{1}\right|\left|\left(\mathrm{y}_{1}-\mathrm{y}_{2}\right)\right|-\max _{\mathrm{x}_{1}, \mathrm{x}_{2} \in X ; \mathrm{y}_{1}, \mathrm{y}_{2} \in \mathrm{Y}}\left|\mathrm{y}_{2}\right|\left|\left(\mathrm{x}_{1}-\mathrm{x}_{2}\right)\right| \quad\left[\text { as }\left|\mathrm{x}_{1}-\mathrm{x}_{2}\right|=\left|\mathrm{x}_{2}-\mathrm{x}_{1}\right|\right] \\
& =\left(\max _{x_{1} \in X}\left|x_{1}\right|\right)\left(\max _{y_{1}, y_{2} \in Y}\left(\mid y_{1}-y_{2}\right) \mid\right)--\left(\max _{y_{2} \in Y}\left|y_{2}\right|\right)\left(\max _{x_{1}, x_{2} \in X}\left|\left(x_{1}-x_{2}\right)\right|\right) \\
& =|X| w\{Y\}-w\{X\}|Y| \text {. }
\end{aligned}
$$


In the similar manner we can show the second inequality.

Hence, we can write that $\mathrm{w}\{\mathrm{XY}\} \geq|\mathrm{w}\{\mathrm{X}\}| \mathrm{Y}|--| \mathrm{X}|\mathrm{w}\{\mathrm{Y}\}|$

(iii) We have, $\frac{\mathrm{w}\{\mathrm{XY}\}}{1+\mathrm{w}\{\mathrm{XY}\}}=\frac{1}{1+1 / w\{X Y\}} \leq \frac{1}{1+\frac{1}{|\mathrm{X}| \mathrm{w}\{\mathrm{Y}\}+\mathrm{w}\{\mathrm{X}\}|\mathrm{Y}|}}$

$$
\begin{aligned}
& =\frac{|\mathrm{X}| \mathrm{w}\{\mathrm{Y}\}+\mathrm{w}\{\mathrm{X}\}|\mathrm{Y}|}{1+|\mathrm{X}| \mathrm{w}\{\mathrm{Y}\}+\mathrm{w}\{\mathrm{X}\}|\mathrm{Y}|} \\
& \leq \frac{\mathrm{w}\{\mathrm{X}\}|\mathrm{Y}|}{1+\mathrm{w}\{\mathrm{X}\}|\mathrm{Y}|}+\frac{|\mathrm{X}| \mathrm{w}\{\mathrm{Y}\}}{1+|\mathrm{X}| \mathrm{w}\{\mathrm{Y}\}}
\end{aligned}
$$

[ last step is due to the fact that, if $\mathrm{x}$ and $\mathrm{y}$ are positive, then $\frac{x+y}{1+x+y}$ $\left.\leq \frac{x+y+2 x y}{1+x+y+x y}=\frac{x}{1+x}+\frac{y}{1+y}\right]$

Theorem 6.4: Let $\mathrm{X}=\left[\mathrm{x}_{1}, \mathrm{x}_{2}\right]$ and $\mathrm{Y}=\left[\mathrm{y}_{1}, \mathrm{y}_{2}\right]$ be two intervals . Then $\mathrm{X} \subseteq \mathrm{Y}$ implies that.......

1) $\mathrm{w}\{\mathrm{X}\} \leq \mathrm{w}\{\mathrm{Y}\}$

2) $\frac{1}{2}[w\{X\}+w\{Y\}] \leq d(X, Y) \leq[w\{X\}+w\{Y\}]$

\section{Proof:}

1) Since $X \subseteq Y$, we have $y_{1} \leq x_{1} \leq x_{2} \leq y_{2}$, from where it clearly follows that ...

$$
\mathrm{w}\{\mathrm{X}\}=\left|\mathrm{x}_{2}-\mathrm{x}_{1}\right| \leq\left|\mathrm{y}_{2}-\mathrm{y}_{1}\right|=\mathrm{w}\{\mathrm{Y}\} .
$$

2) $d(X, Y)=\max \left\{\left|x_{1}-y_{1}\right|,\left|x_{2}-y_{2}\right|\right\}=\max \left\{\left(x_{1}-y_{1}\right),\left(x_{2}-\right.\right.$ $\left.\left.\mathrm{y}_{2}\right)\right\}$.

$$
\begin{aligned}
& \leq y_{2}-x_{2}+x_{1}-y_{1} \\
& =\left(y_{2}-y_{1}\right)+\left(x_{1}-x_{2}\right)=\left|y_{2}-y_{1}\right|+\left|x_{1}-x_{2}\right| \\
& =\left|y_{2}-y_{1}\right|+\left|x_{2}-x_{1}\right| \\
& =w\{X\}+w\{Y\}
\end{aligned}
$$

Again $d(X, Y)=\max \left\{\left|\mathrm{x}_{1}-\mathrm{y}_{1}\right|,\left|\mathrm{x}_{2}-\mathrm{y}_{2}\right|\right\}=\max \left\{\left|\mathrm{x}_{1}-\mathrm{y}_{1}\right|, \mid \mathrm{y}_{2}-\right.$ $\left.\mathrm{x}_{2} \mid\right\}$

$$
\begin{aligned}
& \geq \frac{1}{2}\left(\mathrm{x}_{1}-\mathrm{y}_{1}+\mathrm{y}_{2}-\mathrm{x}_{2}\right)=\frac{1}{2}\left[\left(\mathrm{y}_{2}-\mathrm{y}_{1}\right)+\left(\mathrm{x}_{1}-\mathrm{x}_{2}\right)\right]=\frac{1}{2}\left(\left|\mathrm{y}_{2}-\mathrm{y}_{1}\right|+\left|\mathrm{x}_{1}-\mathrm{x}_{2}\right|\right) \\
& =\frac{1}{2}\left(\left|\mathrm{y}_{2}-\mathrm{y}_{1}\right|+\left|\mathrm{x}_{2}-\mathrm{x}_{1}\right|\right)=\frac{1}{2}[\mathrm{w}\{\mathrm{X}\}+\mathrm{w}\{\mathrm{Y}\}]
\end{aligned}
$$


From "(5)" and "(6)" it follows that ... $\frac{1}{2}[w\{X\}+w\{Y\}] \leq d(X, Y$ )$\leq[\mathrm{w}\{\mathrm{X}\}+\mathrm{w}\{\mathrm{Y}\}]$.

Example: 6.1. Let us take two intervals $X=[0.2,0.5]$ and $Y=[0.1$, 0.6]. Here $X \subseteq Y$.

We can verify the following values......

1) $\mathrm{w}(\mathrm{X})=0.3, \mathrm{w}(\mathrm{Y})=0.5 \Rightarrow \mathrm{w}\{\mathrm{X}\} \leq \mathrm{w}\{\mathrm{Y}\}$

2) $\mathrm{X}^{-1}=\frac{1}{[0.2,0.5]}=[2,5], \mathrm{Y}^{-1}=\frac{1}{[0.1,0.6]}=[1.66,10] \Rightarrow \mathrm{X}^{-1} \subset \mathrm{Y}^{-1}$.

3) $1+\mathrm{X}=[1.2,1.5]$ and $1+\mathrm{Y}=[1.1,1.6] \Rightarrow 1+\mathrm{X} \subset 1+\mathrm{Y}$.

4) $1-X=[0.5,0.8]$ and $1-Y=[0.4,0.9] \Rightarrow 1-X \subset 1-Y$.

5) $\frac{1}{1+X}=\frac{1}{[1.2,1.5]}=\left[\frac{2}{3}, \frac{5}{6}\right]=[0.67,0.83], \frac{1}{1+Y}=\frac{1}{[1.1,1.6]}=[0.62,0.9]$ $\Rightarrow \frac{1}{1+X} \subset \frac{1}{1+Y}$.

6) $\frac{1-Y}{1+Y}=[0.4,0.9][0.62,0.9]=[0.248,0.81]$ and $\frac{1-X}{1+X}=[0.5,0.8]$ $[0.67,0.83]=[0.335,0.664] \quad \Rightarrow \frac{1-X}{1+X} \subset \frac{1-Y}{1+Y}$.

\section{OPERATIONS ON SOME INTERVAL MATRICES}

\subsection{MULTIPLICATION BETWEEN TWO INTERVAL} MATRICES [5]

$$
\text { Let } A=\left(\begin{array}{cc}
{[2,3]} & {[0,2]} \\
{[1,3]} & {[2,3]}
\end{array}\right) \quad B=\left(\begin{array}{c}
{[0,10]} \\
{[6,14]}
\end{array}\right)
$$

Here $\mathrm{A}$ is a matrix of order $2 \times 2$ and $\mathrm{B}$ is a matrix of order $2 \times 1$. So, they are conformable to multiplication and let $\mathrm{A} X \mathrm{~B}=\mathrm{C}$ which is obviously of order $2 \times 1$.By the RULE OF VACANCIES we can write

$\mathrm{C}=[-] \begin{aligned} & \text { The position of first vacancy is } 1^{\text {st }} \text { row and } 1^{\text {st }} \text { column. } \\ & \text { So this vacant position will be filled up by the product }\end{aligned}$ of $1^{\text {st }}$ row of $A$ with $1^{\text {st }}$ column of B, i.e. $[2,3] \times[0,10]+[0,2] \times[6,14]=$ $[0,30]+[0,28]=[0,58]$. Similarly, the second vacant position will be $[1,3] x[0,10]+[2,3] x[6,14]=[0,30]+[12,42]=[12,72]$

[As , $\left[\mathrm{m}_{1}, \mathrm{n}_{1}\right] \mathrm{x}\left[\mathrm{m}_{2}, \mathrm{n}_{2}\right]=[\mathrm{p}, \mathrm{q}]$, where $\mathrm{p}=\min \left(\mathrm{m}_{1} \mathrm{~m}_{2}, \mathrm{~m}_{1} \mathrm{n}_{2}, \mathrm{n}_{1} \mathrm{~m}_{2}\right.$, $\left.\mathrm{n}_{1} \mathrm{n}_{2}\right)$ and $\left.\mathrm{q}=\max \left(\mathrm{m}_{1} \mathrm{~m}_{2}, \mathrm{~m}_{1} \mathrm{n}_{2}, \mathrm{n}_{1} \mathrm{~m}_{2}, \mathrm{n}_{1} \mathrm{n}_{2}\right)\right]$.

$$
C=\left[\begin{array}{c}
{[0,58]} \\
{[12,72]}
\end{array}\right] \text {. }
$$




\subsection{MULTIPLICATION OF AN INTERVAL MATRICX BY A CONSTANT MATRIX}

$$
B=\left(\begin{array}{ll}
0 & -1 \\
1 & -1
\end{array}\right) \quad\left(\begin{array}{ll}
{[-1,1]} & {[1,1]} \\
{[-1,-1]} & {[0,1]}
\end{array}\right)
$$

We have to find out $A B($ here $A B$ is possible).It will be easy to find out the product, if before multiplication we write $B$ as

$$
\begin{aligned}
& B=\left(\begin{array}{ll}
{[0,0]} & {[-1,-1]} \\
{[1,1]} & {[-1,-1]}
\end{array}\right) \begin{array}{r}
\text { Now we can easily calculate } A B \text { as in } \\
\text { the case of } 7.1^{[5]} \text {. }
\end{array} \\
& \text { So , } \quad A B=\left(\begin{array}{ll}
{[1,1]} & {[-2,0]} \\
{[0,1]} & {[0,1]}
\end{array}\right)
\end{aligned}
$$

\section{SOME OPERATIONS ON FUZZY NUMBERS}

Definition(11): Four basic arithmetic operations on fuzzy sets:

Let $\bar{A}$ and $\overline{\mathrm{E}}$ be any two fuzzy numbers and the operation $\bullet \epsilon\{+$ $,--, ., /\}$. Then we can define a fuzzy set $\bar{A} \bullet \bar{E}$ on $\mathbb{R}$, with the help of its $\alpha$-cut, in the form of ...

$$
\overline{\mathrm{A}} \bullet \overline{\mathrm{E}}=\underset{\alpha \in[0,1]}{\mathrm{U}} \quad \alpha^{\alpha}(\overline{\mathrm{A}} \bullet \overline{\mathrm{E}}) \quad \text { where } \alpha(\overline{\mathrm{A}} \bullet \overline{\mathrm{E}})=\alpha \overline{\mathrm{A}} \bullet \alpha \overline{\mathrm{E}}
$$

Definition(12): Alternatively .......

we can define a fuzzy set $\bar{A} \bullet \bar{E}$ on $\mathbb{R}$, with the help of an equation

$$
\begin{gathered}
(\overline{\mathrm{A}} \bullet \overline{\mathrm{E}})(\mathrm{s})=\sup _{\mathrm{s}=\mathrm{x} \bullet \mathrm{y}} \min [\overline{\mathrm{A}}(\mathrm{x}), \overline{\mathrm{E}}(\mathrm{y})], \forall \mathrm{s} \in \mathbb{R} \\
\end{gathered}
$$

Definition(13): Fuzzy numbers $\operatorname{MIN}(\bar{A}, \bar{E})$ and $\operatorname{MAX}(\overline{\mathrm{A}}, \overline{\mathrm{E}})$

If we want to write an ordering of fuzzy numbers, first of all we have to extend the lattice operations min and max on real numbers to the corresponding operations on fuzzy numbers, MIN and MAX.For any fuzzy numbers $A$ and $B$, we define.......

$\operatorname{MIN}(\bar{A}, \bar{E})(s)=\sup \quad \min [\bar{A}(x), \bar{E}(y)]$ and $\operatorname{MAX}(\bar{A}, \bar{E})=\sup$ $\min [\overline{\mathrm{A}}(\mathrm{x}), \overline{\mathrm{E}}(\mathrm{y})]$

$$
\mathrm{s}=\min (\mathrm{x}, \mathrm{y}) \quad \mathrm{s}=\max (\mathrm{x}, \mathrm{y})
$$

we must remember that every fuzzy number is a convex fuzzy set. 
Example:8.1. Let us consider two fuzzy numbers $\bar{A}=[--4,0]$ and $\overline{\mathrm{E}}=[1,5]$, which can be defined by their membership functions as follows .....

$$
\begin{aligned}
& \mu_{\overline{\mathrm{A}}}(\mathrm{x})=\left\{\begin{array}{cl}
(\mathrm{x}+4) / 2 & , \text { when }--4<\mathrm{x} \leq--2 \\
(--\mathrm{x}) / 2 & , \text { when }--2<\mathrm{x} \leq 0 \\
0 & , \text { when } \mathrm{x} \leq-\mathrm{-} \text { and } \mathrm{x}>0
\end{array}\right. \\
& \mu_{\bar{E}}(x)=\left\{\begin{array}{l}
(x-1) / 2, \text { when } 1<x \leq 3 \\
(5--x) / 2, \text { when } 3<x \leq 5 \\
0 \text { otherwise }
\end{array}\right.
\end{aligned}
$$

Calculate $\overline{\mathrm{A}}+\overline{\mathrm{E}}, \overline{\mathrm{A}}-\overline{\mathrm{E}}, \overline{\mathrm{E}}-\overline{\mathrm{A}}, \overline{\mathrm{A}} \cdot \overline{\mathrm{E}}, \overline{\mathrm{A}} / \overline{\mathrm{E}}$.

According to the given conditions,,$\overline{\mathrm{A}}=[2 \alpha-4,--2 \alpha]$ and $\alpha \overline{\mathrm{E}}$ $=[2 \alpha+1,5--2 \alpha]$

Therefore, ${ }^{\alpha}(\bar{A}+\bar{E})=[4 \alpha-3,5-4 \alpha] \quad \forall \alpha \in(0,1] \quad$ i.e. $(\bar{A}+\bar{E})=[--3,5]$

$$
\begin{aligned}
& { }^{\alpha}(\bar{A}-\bar{E})=[4 \alpha-9,-1-4 \alpha] \quad \forall \alpha \in(0,1] \text { i.e. }(\bar{A}-\bar{E})=[--9,--1] \\
& { }^{\alpha}(\bar{E}-\bar{A})=[4 \alpha+1,-4 \alpha+9] \quad \forall \alpha \in(0,1] \quad \text { i.e. }(\bar{E}-\bar{A})=[1,9] \\
& { }^{\alpha}(\bar{A} . \bar{E})=\left[-4 \alpha^{2}+18 \alpha-20,4 \alpha^{2}-10 \alpha\right] \forall \alpha \in(0,1] \quad \text { i.e. }(\bar{A} . \bar{E})=[--20,0] \\
& { }^{\alpha}(\bar{A} / \bar{E})=\left[\frac{2 \alpha-4}{2 \alpha+1}, \frac{-2 \alpha}{2 \alpha+1}\right] \quad \forall \alpha \in(0,1] \quad \text { i.e. }(\bar{A} / \bar{E})=[-4,0]
\end{aligned}
$$

Then, for the resulting fuzzy numbers we can write

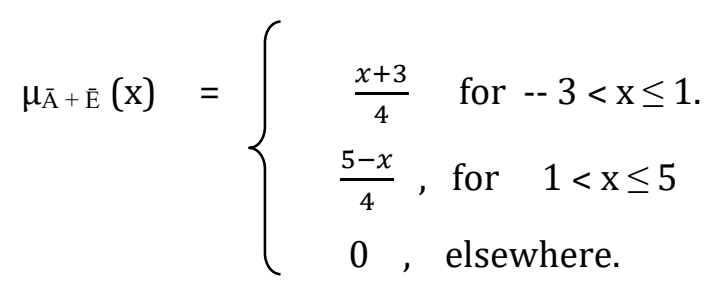

7)

( Resulting membership function of $(\overline{\mathrm{A}}+\overline{\mathrm{E}})$ is illustrated in Figure

$$
\mu_{\overline{\mathrm{A}}-\mathrm{E}}(\mathrm{X})= \begin{cases}\frac{x+9}{4}, & \text { for }--9<\mathrm{X} \leq--5 . \\ \frac{-1-x}{4}, & \text { for }--5<\mathrm{X} \leq--1 \\ 0, & \text { elsewhere. }\end{cases}
$$


8)

( Resulting membership function of $(\overline{\mathrm{A}}-\overline{\mathrm{E}})$ is illustrated in Figure

$$
\mu_{\overline{\mathrm{E}}-\overline{\mathrm{A}}}(\mathrm{X})=\left\{\begin{array}{cl}
\frac{x-1}{4} & \text { for } 1<\mathrm{X} \leq 5 . \\
\frac{9-x}{4}, & \text { for } 5<\mathrm{X} \leq 9 \\
0, & \text { elsewhere. }
\end{array}\right.
$$

9)

( Resulting membership function of $(\overline{\mathrm{E}}-\overline{\mathrm{A}})$ is illustrated in Figure

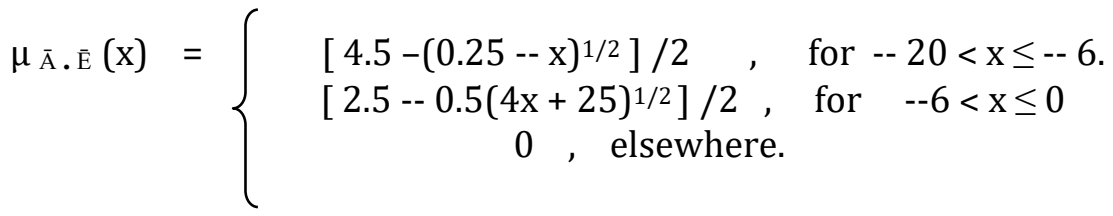
10)

(Resulting membership function of $(\overline{\mathrm{A}} \cdot \overline{\mathrm{E}})$ is illustrated in Figure

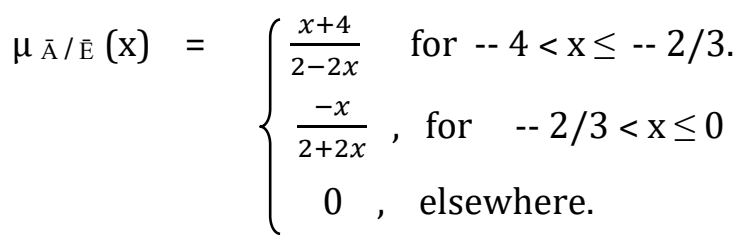

( Resulting membership function of $(\overline{\mathrm{A}} / \overline{\mathrm{E}})$ is illustrated in Figure 11)

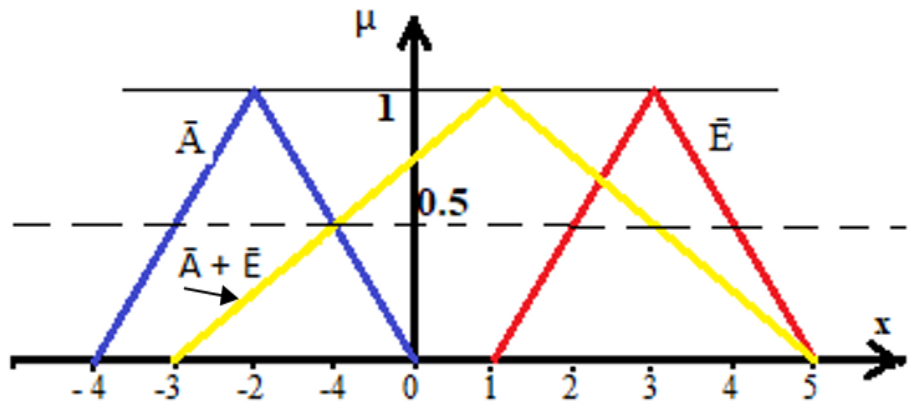

Figure 7 


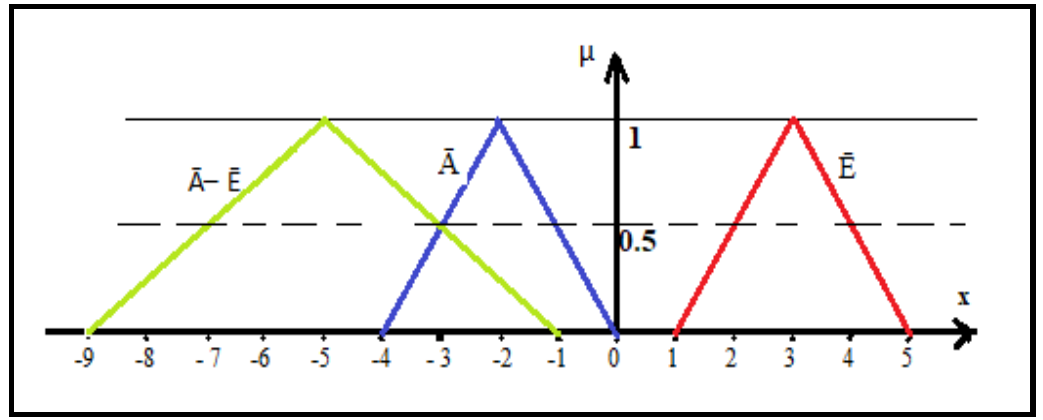

Figure 8

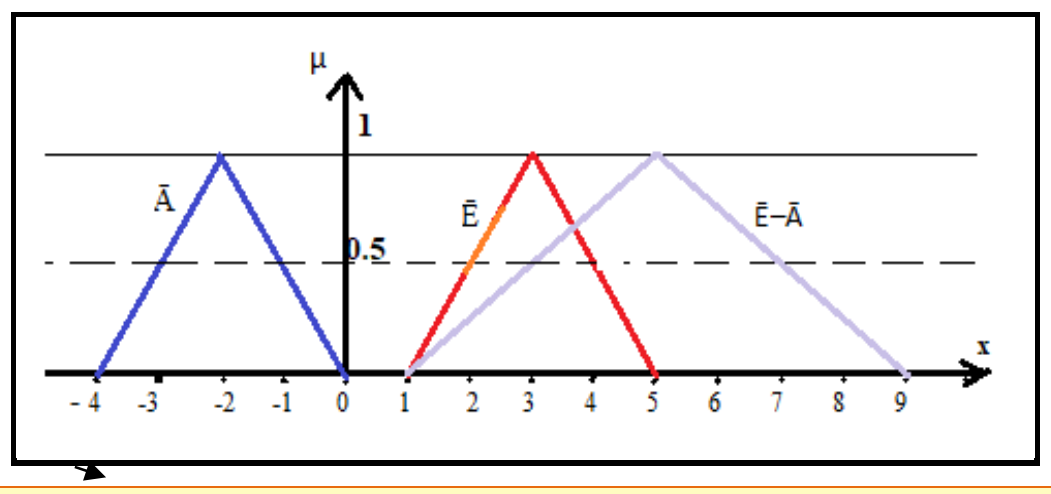

Figure 9

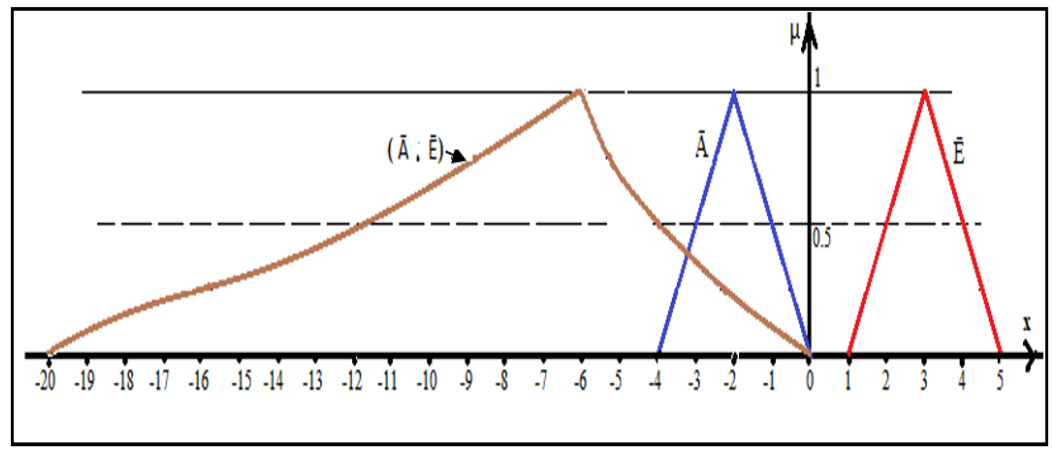

Figure 10

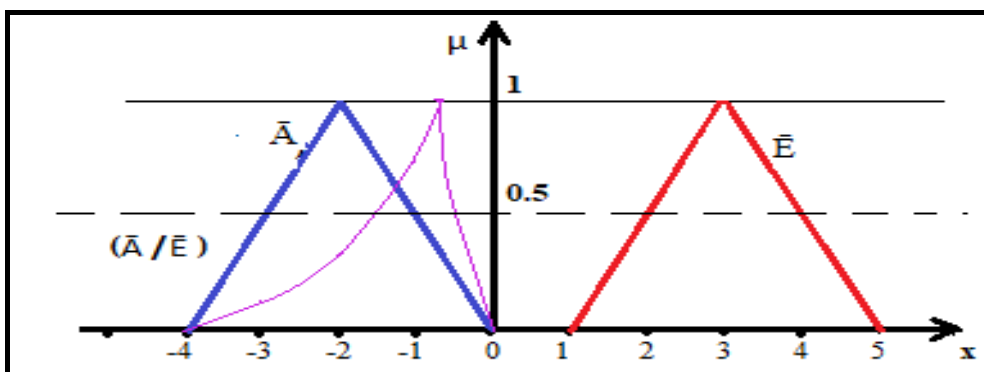

Figure 11 
Example:8.2. Calculate $\operatorname{MIN}(\overline{\mathrm{A}}, \overline{\mathrm{E}})$ and $\operatorname{MAX}(\overline{\mathrm{A}}, \overline{\mathrm{E}})$ for the two fuzzy numbers $\overline{\mathrm{A}}=[-6,6]$ and $\overline{\mathrm{E}}=[-4,0]$ which can be defined as follows ......

$$
\begin{array}{r}
\mu_{\bar{A}}(x)=\left\{\begin{array}{l}
(x+6) / 6, \text { when }-6<x \leq 0 \\
(6--x) / 6, \text { when } 0<x \leq 6 \\
0 \quad \text { when elsewhere }
\end{array}\right. \\
\mu_{\bar{E}}(x)=\left\{\begin{array}{l}
(x+4) / 2, \text { when }--4<x \leq--2 \\
(-x) / 2, \text { when }--2<x \leq 0 \\
0 \text { otherwise }
\end{array}\right.
\end{array}
$$

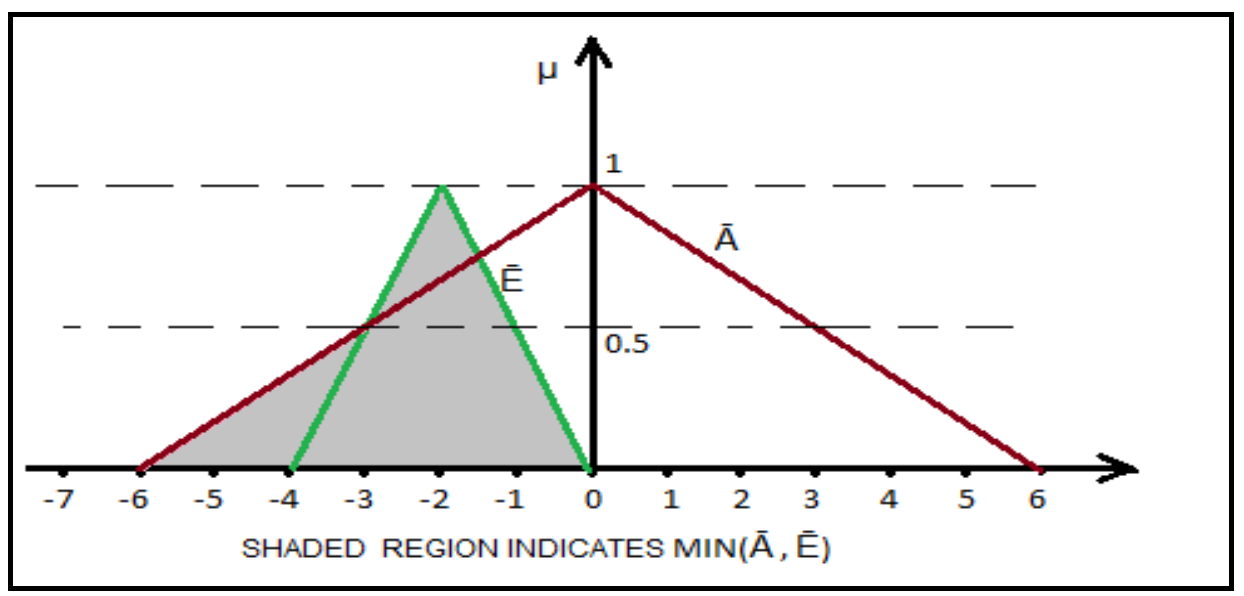

Figure 12

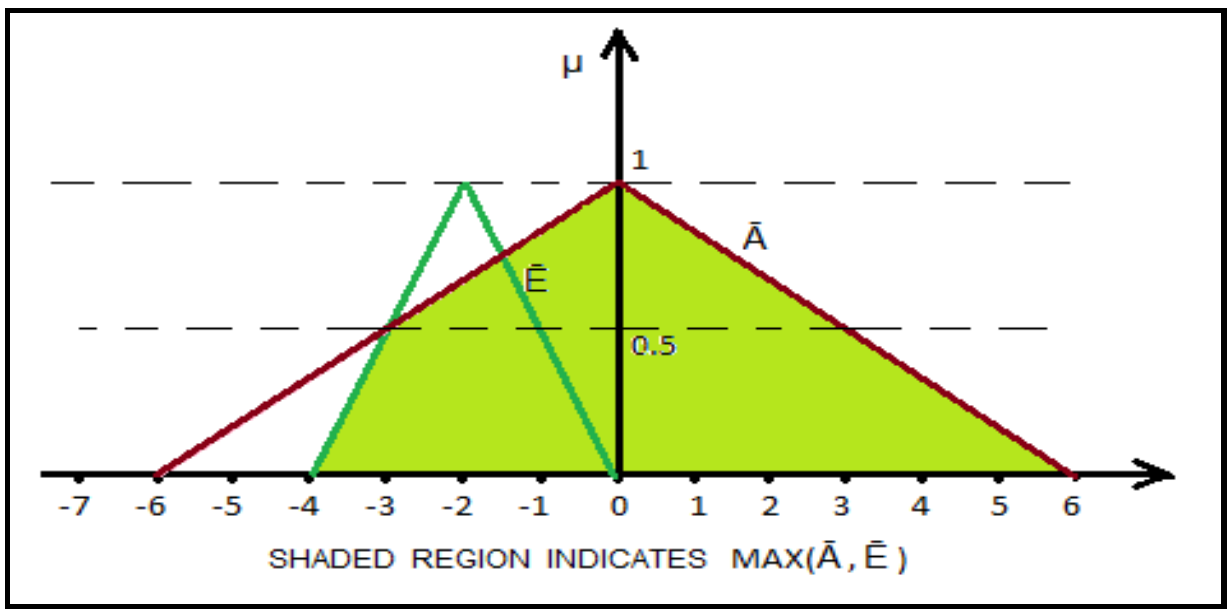

Figure 13

$$
\mu_{\operatorname{MIN}(\bar{A}, \overline{\mathrm{E}})}(\mathrm{x})=\left\{\begin{array}{c}
0, \quad \text { when } \quad \mathrm{x}<--6 \text { and } \mathrm{x}>0, \quad \text { illustrated in Figure } 12 \\
(\mathrm{x}+6) / 6, \text { when }--6<\mathrm{x} \leq--3 \\
(\mathrm{x}+4) / 2, \text { when }--3<\mathrm{x} \leq--2 \\
(--\mathrm{x}) / 2, \text { when }--2<\mathrm{x} \leq 0
\end{array}\right.
$$




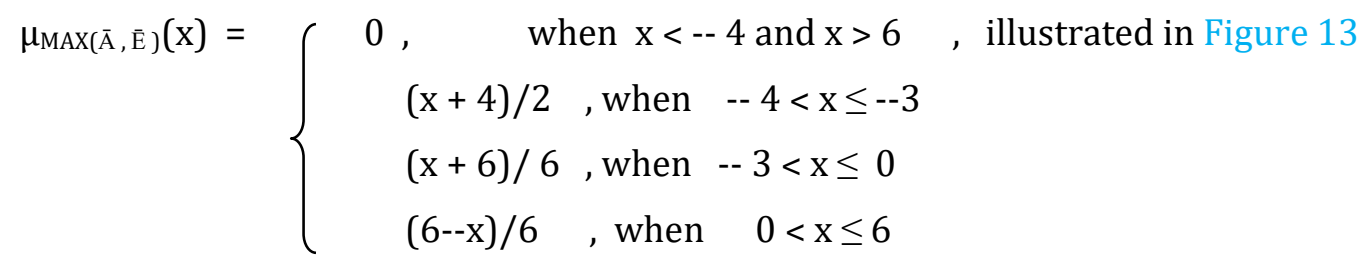

\section{FUZZY MAPPING}

Let $\mathrm{S}$ be a nonempty set in $\mathrm{R}^{\mathrm{n}}$ (denoted by $\mathrm{E}$ ), a mapping $\mathrm{f}: \mathrm{S} \rightarrow \mathrm{F}_{0}$ is said to be a fuzzy mapping, where $\mathrm{F}_{0}$ is the set of all fuzzy numbers.

Definition(14): [6] The lower-level set of $f$, denoted by $S_{u}(f)$, is a subset of $E$ defined by

$$
S_{u}(f)=\{x \mid x \in S \text { and } f(x) \leq u\} \text {, where }\left(u \in F_{0}\right) .
$$

The upper-level set of $\mathrm{f}$, denoted by $\mathrm{Su}(\mathrm{f})$, is a subset of $\mathrm{E}$ defined by

$$
S^{U}(f)=\{x \mid x \in S \text { and } f(x) \geq u\} \text {, where }\left(u \in F_{0}\right) \text {. }
$$

Theorem 9.1: In the lower-level set of $\mathrm{f}$, if the elements are $\mathrm{x}_{1} \leq \mathrm{x}_{2} \leq \mathrm{x}_{3} \leq \ldots \ldots \ldots$ $\leq \mathrm{x}_{\mathrm{n}}$ for which

$\mathrm{f}\left(\mathrm{x}_{1}\right) \leq \mathrm{f}\left(\mathrm{x}_{2}\right) \leq \mathrm{f}\left(\mathrm{x}_{3}\right) \leq \ldots \ldots \ldots \leq \mathrm{f}\left(\mathrm{x}_{\mathrm{n}}\right)$, then the sequence $\left(\mathrm{f}\left(\mathrm{x}_{\mathrm{n}}\right)\right)_{\mathrm{n} \in \mathrm{N}}$ is convergent and converges to $\mathrm{u}$ ( supremum) .

Proof: By the definition [6] of the lower-level set of $\mathrm{f}$ it is clear that $\left\{\mathrm{f}\left(\mathrm{x}_{\mathrm{n}}\right)\right\}$ is bounded above by $\mathrm{u}$ and since the sequence $\left(\mathrm{f}\left(\mathrm{x}_{\mathrm{n}}\right)\right)$ is monotonically increasing, so the sequence is convergent and converges to the supremum $u$

i.e. its limit is $u$.

Similar is the following theorem.

Theorem 9.2: In the upper-level set of $f$, if the elements are $x_{1} \geq x_{2} \geq x_{3} \geq \ldots \ldots . . \geq$ $\mathrm{x}_{\mathrm{n}}$ for which

$f\left(x_{1}\right) \geq f\left(x_{2}\right) \geq f\left(x_{3}\right) \geq \ldots \ldots \ldots \geq f\left(x_{n}\right)$, then the sequence $\left(f\left(x_{n}\right)\right)_{n \in N}$ is convergent and converges to $u$ (infimum ).

\section{CONCLUSION}

Most mathematical tools for computing, formal modelling and reasoning are crisp,deterministic and precise in many characters.However several problems in economics,environment,engineering,social science,medical science etc. do not always involve crisp data in real life. Consequently,we can not successfully use the classical method because of various types of uncertainties presented in the problem.There lies the usefulness of study Fuzzy Mathematics.

The work that has been done through this paper ,I hope, surely create some impacts on the beginners and motivate them as well. 


\section{REFERENCES}

A. Kaufmann and M. N. Gupta (1991). -- Introduction to Fuzzy Arithmetic Theory and Applications. New York, NY: Van Nostrand Reinhold

G. Alefeld and J. Herzberger (1983). - Introduction to interval computations. New York, NY : Academic Press.

H-J. Zimmermann. (2011) -Fuzzy set theory - and its application. 4th edition. ISBN-978-94-010-0646n - 0 .

I. N. Herstein (n.d.). -- Topics in Algebra.

John N. Mordeson, Premchand S. Nair (2001). -- Fuzzy Mathematics. ISBN - 978 - 3 - 7908 - 1808 - 6. Retrieved from https://link.springer.com/book/10.1007/978-3-7908-1808-6

S. Nanda, N. R. Das (2021).-- Fuzzy Mathematical concepts 